\title{
Are moral norms rooted in instincts? The sibling incest taboo as a case study
}

\author{
Nathan Cofnas ${ }^{1}$ (D)
}

Received: 12 December 2019 / Accepted: 17 August 2020 / Published online: 25 August 2020

(c) The Author(s) 2020

\begin{abstract}
According to Westermarck's widely accepted explanation of the incest taboo, cultural prohibitions on sibling sex are rooted in an evolved biological disposition to feel sexual aversion toward our childhood coresidents. Bernard Williams posed the "representation problem" for Westermarck's theory: the content of the hypothesized instinct (avoid sex with childhood coresidents) is different from the content of the incest taboo (avoid sex with siblings) — thus the former cannot be causally responsible for the latter. Arthur Wolf posed the related "moralization problem": the instinct concerns personal behavior whereas the prohibition concerns everyone. This paper reviews possible ways of defending Westermarck's theory from the representation and moralization problems, and concludes that the theory is untenable. A recent study purports to support Westermarck's account by showing that unrelated children raised in the same peer groups on kibbutzim feel sexual aversion toward each other and morally oppose third-party intra-peer-group sex, but this study has been misinterpreted. I argue that the representation and moralization problems are general problems that could potentially undermine many popular evolutionary explanations of social/moral norms. The cultural evolution of morality is not tightly constrained by our biological endowment in the way some philosophers and evolutionary psychologists believe.
\end{abstract}

Keywords Representation problem · Moralization problem · Incest taboo · Westermarck effect · Evolutionary psychology

\section{Introduction}

There is a widespread prohibition on brother-sister marriage across human cultures, reflecting a widespread taboo on brother-sister sex (Wolf and Durham 2004). Some scholars believe the sibling incest taboo has a clear biological basis, and they see it

Nathan Cofnas

nathan.cofnas@balliol.ox.ac.uk

1 Balliol College, Oxford OX1 3BJ, UK 
as a paradigm case of biology influencing (or determining) a social norm. Following Westermarck (1891), they argue that, in order to avoid close inbreeding, we evolved to feel sexual aversion toward people with whom we are raised as young childrenpeople who are almost always our biological siblings. This innate impulse, which came to be known as the "Westermarck effect," expresses itself as a norm prohibiting sibling sex. Ruse and Wilson (1986: 184) wrote that the following explanation of the incest taboo is "widely accepted":

Lowered genetic fitness due to inbreeding led to the evolution of the juvenile sensitive period [to develop sexual aversion] by means of natural selection; the inhibition experienced at sexual maturity led to prohibitions and cautionary myths against incest or (in many societies) merely a shared feeling that the practice is inappropriate. Formal incest taboos are the cultural reinforcement of the automatic inhibition, an example of the way culture is shaped by biology.

Wilson (1998: 196) later acknowledged that some cultures might have recognized the negative consequences of close inbreeding for offspring, and instituted the taboo for this reason. But he reiterated that, in the majority of cases, "[t]he taboos seem likely to have arisen from the Westermarck effect," and he referred to the process of "translating the Westermarck effect into incest taboos." Lieberman and Lobel (2012: 27) argue that new evidence bolsters Westermarck's theory that (in their words) "personal sexual aversions that target childhood associates manifest themselves on the cultural stage as proscriptions against incest." Others stop short of endorsing this hypothesis, but treat it as a serious contender. De Waal (1999: 99) says that an "intriguing question is whether the incest taboo merely serves to formalize and strengthen the Westermarck effect or whether it adds a substantially new dimension."

The causal story Westermarck gives for how we get from a biological disposition to a social norm faces some often-overlooked conceptual challenges. Wilson flouts these challenges when he asserts that Westermarckian inhibitions get "translat[ed]" into the incest taboo. Even de Waal, who does not necessarily jump on the Westermarck bandwagon, apparently sees no problem in principle with the idea that the inhibition could simply be "formalize[d]" in the taboo. But private inhibitions and social taboos are very different things. When we discover a biological disposition that seems to correspond to a norm or institution, we cannot automatically conclude that the latter is rooted in the former. What it would even mean for a norm to be "rooted" in a biological disposition is itself unclear.

Another set of examples illustrates the conceptual problems we face in seeking the biological basis of norms. Street (2006: 115) asks us to consider some "judgements about reasons" including the following: "The fact that something would promote the interests of a family member is a reason to do it." "We have greater obligations to help our own children than we do to help complete strangers." What accounts for the widespread acceptance of these judgements? According to Street: "Evolutionary biology offers powerful answers to [this question], very roughly of the form that these sorts of judgements about reasons tended to 
promote survival and reproduction much more effectively than the alternative judgements." The theory of kin selection, she says, explains why we accept the propositions listed above.

But there is a huge gap between the instincts predicted by the theory of kin selection and the evaluative judgements formulated by Street. For one thing, the parental instinct that leads us to care more about the welfare of our own children than the welfare of strangers has a different content than the widely accepted moral/legal principle that "We have greater obligations to help our own children than we do to help complete strangers." If I have children, my instinct should lead me to want to help these children. Insofar as I care about other people's preferences, I should want them to be more favorably disposed toward my children than toward their own. Furthermore, Street's propositions have a moral dimension that the instincts predicted by kin-selection theory do not have.

Street (2006: 120) does acknowledge that there is often a gap of some kind between instinctual dispositions and the (supposedly) corresponding evaluative judgements when she writes:

I do not mean that we automatically or inevitably accept the full-fledged evaluative judgements that line up in content with our basic evaluative tendencies....My point here is instead the simple and plausible one that had the general content of our basic evaluative tendencies been very different, then the general content of our full-fledged evaluative judgements would also have been very different, and in loosely corresponding ways.

But, as noted above, the content of our parental instinct (give preferential treatment to my children) does not "line up" with the content of the corresponding evaluative judgement (everyone ought to give preferential treatment to their children). It is not clear how or if the instinct is related to the judgement at all. So it is premature to conclude that, had the instinct been different, our evaluative judgement would be different in a "loosely corresponding" way.

This paper examines the sibling incest taboo as a case study to understand the relationship between biological dispositions and social norms, particularly moral norms. The analysis will bring out a number of conceptual problems that arise when we study the biological underpinnings of social/moral norms generally, and incest taboos specifically. Ultimately, I argue that Westermarck's hypothesis cannot explain the sibling incest taboo.

The following section outlines the representation and moralization problems (Williams 1983; Wolf 2004b), which concern two different ways in which the Westermarck effect and the incest taboo differ in their content. Given that the Westermarck effect targets childhood coresidents and personal behavior, and the incest taboo targets siblings and everyone's behavior, it seems that the former cannot be responsible for the latter. The third section clarifies what "content" means in this context, and considers and rejects a proposed solution to the representation problem. The fourth section considers a possible solution to the moralization problem - what is termed the vicarious disgust hypothesis-and concludes that it is empirically unsupported. The fifth section considers alternative theories 
of the sibling incest taboo, focusing on the idea that it was established to promote social cohesion within families, or in response to recognition of the dangers of inbreeding. I argue that versions of the representation and moralization problem apply to the former but not the latter theory. The final section argues that the representation and moralization problems are general problems that could potentially undermine many popular evolutionary explanations of social/moral norms.

\section{The representation and moralization problems}

Williams (1983) posed the "representation problem" for Westermarck's hypothesis: the content of the Westermarck effect-feel sexual aversion toward childhood coresidents-is different from the content of the incest taboo-do not have sex with biological siblings. Even if the Westermarck effect is real, he argued, it could have nothing to do with the incest taboo, since the aversion and the taboo concern different behaviors. If the Westermarck effect gave rise to a moral norm it would be do not have sex with childhood coresidents.

Although Williams and subsequent commentators have treated the representation problem as a challenge for Westermarck's hypothesis specifically, the problem applies in virtually the same form to other theories about how instincts give rise to moral norms. Consider Street's (2006) suggestion that our innate kin-directed altruistic tendencies (implanted in us by kin selection) gave rise to the norm saying that we have a reason to promote the interests of family members. This theory is subject to the representation problem because natural selection did not give us an instinct to prefer our family members. Rather, it gave us a disposition to be more altruistic toward people who exhibit cues that were historically correlated with being our family members. Such cues presumably include spending a lot of time with and/or growing up in close proximity to oneself (see Lieberman et al. 2007; Silk 2009). But according to the moral norm mentioned by Street we might have greater obligations toward a cousin we barely know than we have toward a classmate who grew up with us, even if the latter elicits our innate altruistic response much more strongly.

Wolf (2004b: 11-12) posed the "moralization problem" for Westermarck's hypothesis: the content of the Westermarck effect concerns one's own behavior, whereas the content of the incest taboo concerns everyone's behavior. That is, there is an amoral-moral gap in content. As will be discussed in more detail in the following section, the content of the Westermarck effect (and many other adaptive dispositions) concerns the behavior of a specific person toward another specific person(s). As a general rule, the content of moral norms is not relativized to a particular person or concrete relationship. The content of the Westermarck effect, avoid sex with my childhood coresident( $s$ ), is different in two ways from the content of the incest taboo, everyone ought to avoid sex with their sibling $(s)$.

One might be tempted to think that the moralization problem has an easy solution. Isn't it obvious that a strong personal desire should lead us to endorse a moral norm that gives free expression to the desire? Since moral norms have to be universalizable, the content of the norm would have to take on a universalizable form, and this explains why the content of the disposition must change (so one could argue). 
But this a mistake. First, there is no obvious reason why we should think that, in general, strong desires will give rise to moral norms supporting the desired behavior. If most people have a desire to $X$, why create a norm saying that everyone ought to $X$ ? Why would a desire to $X$ per se make us care whether or not other people $X$ ? Second, if we have a strong personal desire to $X$, this can be the basis for establishing a moral norm that prohibits or curtails, not demands, Xing. Street (2006) says that our impulse to help our kin leads us to endorse the norm that family members should help each other. But, as a matter of fact, many if not all societies-including all nomadic foragers (Boehm 1999)—have anti-nepotism norms (sometimes codified in law) that prohibit certain forms of family-directed support. In short, there is no reason why we should expect any particular personal desire (that does not directly concern third-party behavior) to be moralized.

We often face the following situation: we believe we have identified a naturally selected biological disposition, $D$, that prompts behavior that is similar to that prescribed by a social norm, $N$. We assume that $D$ must have given rise to $N$-that the former is somehow causally responsible for the latter. But on closer inspection we find that the behaviors and attitudes produced by $D$ are actually quite different from those demanded by $N$. Often $D$ is an amoral instinct while $N$ is moralized. If $D$ really is causally responsible for $N$, it was not by a simple process of "formaliz[ing]" widely shared individual dispositions. It may not even be necessary to refer to $D$ at all in order to explain $N$.

\section{The content of biological dispositions and social norms}

Street (2006) and Williams (1983) refer to the "content" of biological dispositions, which they compare with the "content" of corresponding social/moral norms. Street does this to call attention to supposed similarities-Williams, to differences-in the content of dispositions and norms. But what is the content of a disposition or a norm?

\section{Social norms}

Sripada and Stich (2006: 281) define "norms" as "rule[s] or principle[s] that specif[y] actions that are required, permissible, or forbidden independently of any legal or social institution." Norms can be formally enforced, but they do not have to be. Sripada and Stich describe norms as having "independent normativity." That is to say, conforming to a norm is seen by the community that accepts it as being an end in itself. (In practice, of course, people often have ulterior motives.) Machery and Mallon (2010: 12) similarly note that the "content [of norms] essentially involves deontic concepts, such as SHOULD or OUGHT." Although Sripada and Stich say that norms regulate "actions," which suggests physical behavior, norms can also require, permit, or forbid emotional and attitudinal responses (see Machery and Mallon 2010: 12). 
There is more to say about the concept of norms, but the definition given above is sufficient for the present discussion. Westermarck, Street, et al. are essentially interested in the origin of the collectively accepted rules and principles regulating our behavior and attitudes.

Social norms may or may not be explicit. Some are never-or rarely-explicitly stated. For example, there is a rarely stated norm that you do not sit directly next to a stranger in a public place as long as there are other seats available. ${ }^{1}$ Most people probably follow this rule without having been taught it explicitly and without thinking about it consciously. We might become conscious of such norms only when they are violated. Nevertheless, unstated norms are always stateable in principle. It is always possible to state the rules or principles to which people in a community expect each other to conform.

The content of a social norm is the semantic content conveyed when the norm is stated. We obtain the content of a norm simply by disquotation. The content of "do not steal" is do not steal. What exactly constitutes "stealing" may not be easy to articulate. But the content of the norm is embodied in its more or less vague linguistic expression as a proposition/imperative. The contents of Street's "evaluative judgements" are exactly what is expressed when those judgements are stated.

\section{Biological dispositions}

Instincts are behavioral adaptations to respond in (historically) adaptive ways to certain environmental conditions. They have two component parts, namely, a part that tracks states of the environment and a part that executes a response. In classical ethology these are called "innate releasing mechanisms" and "fixed action patterns," respectively (Eibl-Eibesfeldt 1989: chapter 2). The way in which instincts operate as proximate causes of our behavior can be described by verbal propositions. A description of an instinct has the form "I exhibit response $R$ when faced with stimulus $S$," where $S$ is the cue(s) that the world-tracking part of the instinct uses to determine when to trigger $R$. The content of an instinct corresponds to the content of the proposition describing the proximate mechanisms that constitute the instinct. The content of the Westermarck effect is clearly different from that of the incest taboo.

Instincts are by definition adaptations, but they do not derive their content (in the sense described above) in virtue of being adaptations. Biological dispositions that are not adaptations - for example, accidental byproducts of instincts-have content in virtue of being describable with propositions of the form "I exhibit response $R$ when faced with stimulus $S$. ." If the Westermarck effect were real but, contra Westermarck, not an adaptation, it would still have the same content- "I avoid sex with

\footnotetext{
1 Incidentally, Eibl-Eibesfeldt (1989: 336-339) argues that this norm has a biological basis.

2 Such dispositions would lack teleosemantic content, which requires the mechanism that "consumes" a representation of the world to have a proper function based on its evolutionary history, which in turn determines the content of the representation (Millikan 1989). Because the evolutionary history of a biological disposition is not as such relevant to how we normally experience it, the notion of "content" upon which the representation problem is based cannot be grounded in evolutionary history.
} 
childhood coresidents" - and this content could be compared with that of the incest taboo.

\section{Another way to determine the content of dispositions: a solution to the representation problem?}

The most promising solution to the representation problem was proposed by Sesardic (1998). He argued that, according to Westermarck's hypothesis, it does not matter what property in our siblings objectively causes our sexual aversion toward them. It only matters what property we subjectively experience as the cause of the inhibition. When we find ourselves unattracted to our siblings, we might "make sense of [our] own aversion....in terms of the most 'natural' category available (close kin relationship), and 'feel' that what is repellent...is sex with close relatives" (Sesardic 1998: 424). To explain our aversion, we "choose the line of least resistance and simply reach for the more meaningful social category like brother or sister, rather than a seemingly irrelevant and queer characteristic like someone with whom I spent the first years of my childhood' (Sesardic 2004: 114-115).

In light of Sesardic's observation, we need to distinguish between the objective content and the subjectively experienced content of biological dispositions. Williams (1983) implicitly assumed that these two kinds of content are always the same, but there is no reason to think that they are. Propositions expressing the objective (O) and the subjectively experienced (SE) content of a disposition have the same form, namely, "I exhibit response $R$ when faced with stimulus $S$," but they may designate different $S$ 's. When faced with an object exhibiting $R$-eliciting stimulus $S_{O}$, we may feel or believe that $R$ is being elicited by some other property associated with the object, $S_{S E}$. Sometimes $S_{O}$ and $S_{S E}$ may be the same, sometimes they may be different.

However, there is a sense in which Sesardic's solution to the representation problem assumes what needs to be explained. He notes that brother and sister are "natural" and "meaningful" social categories whereas childhood coresident is not. That's true. But why are the former categories socially meaningful in the first place? These are salient, meaningful categories because we have social norms regulating the relationship between brothers and sisters-norms saying, for example, that they have certain obligations toward each other and prohibiting sex and marriage between them. To explain how the categories brother and sister became significant, we have to explain why our ancestors decided to create social norms referring to these categories, thereby causing them to be significant.

Silk (2009: 3243) claims that "other primates distinguish kin from non-kin, form enduring relationships with their offspring, selectively groom, support and reconcile conflicts with their relatives and are aware of the kinship relationships between other group members." But the evidence she reviews does not support the idea that nonhuman primates are "aware" of relationships between kin qua kin. Rather, they instinctually bond with childhood associates, and are aware of similar bonds between third parties. Silk notes that the "primary basis for kin recognition...in primates" is "[c] lose association early in life....The importance of early familiarity is supported 
by the evidence that captive 'foster' mothers routinely accept strange infants, even when they are not the same sex, exact ages or species as their own infants" (3244). There is no basis for thinking that nonhuman primates experience this bonding as "kin recognition," or have any such concept. They simply develop special feelings for other individuals - who do not necessarily even need to be the same species, let alone close kin - with whom they have specific kinds of close interaction.

We have to imagine a time before social norms regulating familial relationships were established, when our ancestors were equipped with dispositions to be altruistic and feel sexual aversion toward those with whom they had close associations when growing up (who were often but not always close kin). Would brother and sister have been more "natural" categories than childhood coresident for these early humans? The answer is not obvious. Childbirth is a conspicuous event, and under normal circumstances the bond between mothers and their children is strong in all primates. It is plausible that the categories mother and offspring would have been easy to recognize. Once mother and offspring became significant categories, perhaps it would have been natural to recognize the category of offspring born to a single woman, i.e., maternal siblings. On the other hand, early human children probably often grew up and had intimate relationships with people who were not born to the same mother. Often enough these relationships might have produced feelings of altruism and sexual aversion greater than or comparable to what people felt toward their biological siblings, particularly siblings separated in age by several years.

One of the main sources of evidence for the Westermarck effect comes from studies of arranged marriages in Taiwan. In so-called "minor marriages," a bride was adopted by the husband's family as an infant and the future couple was raised as if they were siblings. Wolf (2004a) found evidence that these marriages were marked by sexual dissatisfaction reflected in lower fertility and higher divorce rates. However, if the future husband was at least nine years older than bride, there was no evidence of sexual dissatisfaction. In the same vein, Lieberman et al. (2007) found that the strength of sibling altruism depends on the amount of time spent together before age 18. It is thus reasonable to suppose that, historically, biological siblings separated in age by several years would have frequently failed to develop strong Westermarckian inhibitions or feelings of altruism, while unrelated children sometimes formed strong bonds. Childhood coresident-someone with whom one grew up in intimate contact - could conceivably have been recognized as a significant category, but for some reason it was not.

Even if Sesardic's solution solved the representation problem-and I have suggested reasons to doubt that it does-it would not solve the moralization problem. If I have the subjective experience of feeling sexual aversion toward my sibling (qua sibling), why should I support a rule that you cannot have sex with your sibling? 


\section{The vicarious disgust hypothesis: a solution to the moralization problem?}

Suppose for the sake of argument that the Westermarck effect is real and that its subjectively experienced content is avoid sex with my siblings. Even still, the content of the Westermarck effect does not concern third-party behavior. There is no logical link between the biological disposition to avoid sex with my siblings and the moral norm everyone should avoid sex with their siblings. The process described by Westermarck requires a psychological mechanism that transforms personal sexual aversions into moral opposition to third parties engaging in sexual behavior analogous to that which we find aversive.

Westermarck (1921) explains the process by which sexual aversion toward our own close kin (due to the Westermarck effect) gives rise to a moral/legal prohibition on incest as follows: "sexual indifference is very generally combined with sexual aversion when the act is thought of....And....aversions which are generally felt readily lead to moral disapproval and prohibitory customs or laws" (197-198). Because "[p]ersons who have been living closely together from childhood are as a rule near relatives[,]...their aversion to sexual relations with one another displays itself in custom and law as a prohibition of intercourse between near kin" (193). We can call this the vicarious disgust hypothesis.

The vicarious disgust hypothesis makes two claims. First, third-party incest triggers empathic disgust (which is rooted in our Westermarckian aversion toward our childhood coresidents). Second, people judge disgusting actions to be morally wrong - that is, disgust leads us to condemn acts that would otherwise be considered morally neutral. But the second claim is not well supported, and there is direct empirical evidence against the idea that Westermarckian aversions lead to vicarious disgust and moral condemnation.

The idea that we judge disgusting actions to be morally wrong is intuitively plausible, and is often assumed to be correct by psychologists. Is it true? There is evidence that inducing disgust (especially via olfaction) can amplify the moral condemnation of acts that would be judged immoral in the absence of the disgust prime. But even defenders of the amplification theory acknowledge that the amplification effect is small and usually only found in individuals with certain personality traits such as low mindfulness or high disgust sensitivity (Schnall et al. 2015). In any case, the vicarious disgust hypothesis assumes not that disgust amplifies moral condemnation but that it leads us to condemn acts that would otherwise be judged morally neutral. The evidence for this is weak.

Wheatley and Haidt (2005) gave highly hypnotizable subjects a posthypnotic suggestion to feel disgust when they encountered one of two words ("often" or "take"). Subjects then read a vignette describing innocuous behavior: a student council representative "[tries to take/often picks] topics that appeal to both professors and students in order to stimulate discussion" (782). Wheatley and Haidt report that "[p] articipants judged the actions to be more morally wrong when their hypnotic word was present" (782). This study has been widely cited to support the claim that disgust causes moral condemnation. However, it is questionable whether Wheatley and 
Haidt's subjects thought that the behavior described in the vignette was actually immoral. When moral evaluations were converted to a 100-point scale (from not at all morally wrong to extremely morally wrong), the average ratings for the control and experimental groups were 2.7 and 14.0, respectively. As May (2014: 129) observes, a mean rating of 14 on a 100 -point scale "still seems to count the action as not morally wrong."

Several other studies have found that disgust can cause people to condemn (what would normally be regarded as) morally neutral acts, but the effect is small. Landy and Goodwin (2015: 530) point out that the effect is smaller in unpublished than published studies, indicating possible publication bias in the literature. Both liberals and conservatives say that "[w]hether or not someone did something disgusting" is one of the factors they consider when deciding if their action was wrong, with conservatives assigning slightly more evaluative importance to disgustingness (Haidt and Graham 2007). However, as Pizarro et al. (2011: 268) note, "there is a plethora of behaviors that are judged by most people as disgusting but not immoral, such as eating pig brains or picking one's nose in private." So disgust does not lead inevitably to moral condemnation. If our disgust toward incest is what motivates us to establish the incest taboo, there must be something special about Westermarckianbased sexual disgust that makes us morally condemn the disgusting act in others.

Lieberman and Lobel (2012) claim to provide evidence for a direct link between Westermarck effect-induced sexual disgust and moral opposition to the disgusting sexual behavior. But a closer look at their data suggests that this conclusion is highly questionable.

Children in Israeli kibbutzim were traditionally raised from birth in same-age peer groups composed of around 15 nonrelatives. Growing up they would eat, sleep, and (at least as children) shower together. Each day, they would spend at most three hours with their parents and biological siblings. A frequently cited piece of evidence for the Westermarck effect is the (alleged) finding that when these children grew up, they did not feel sexual attraction toward each other despite the fact that there was no formal prohibition on sex between them (Shepher 1971, 1983; Wolf 2004b).

Lieberman and Lobel (2012) conducted a survey of communally raised kibbutz children to measure their sexual attraction to their peers versus siblings, and also their moral attitudes toward peer versus sibling sex. They claim that their results support Westermarck's theory that childhood coresidence leads to sexual aversion and moral condemnation of the aversive act. Sexual aversion toward peer-group members was positively correlated with time spent residing with them, and moral opposition to third-party intra-peer-group sex was positively correlated with subjects' own aversion toward their peers. Thus, they conclude, "personal sexual aversions shape attitudes relating to third-party sexual behavior" (26). Let's look more closely at the evidence for this.

Because children joined the kibbutzim at different ages, peer-group members resided with each other for varying lengths of time. Lieberman and Lobel predicted that the kibbutzniks' sexual aversion toward each of their peers would be correlated with the amount of time they spent together before age 18. Following Westermarck's logic, they also predicted that the total amount of time people spent in communal 
peer groups-and the degree of aversion they felt toward their peers-would be associated with greater moral opposition to third-party intra-peer-group sex.

Lieberman and Lobel (2012) conducted two surveys. In both surveys, respondents reported their feelings about kissing as well as having sex with each of their opposite-sex peers on a scale ranging from " -5 (very disgusting) to 5 (very appealing); midpoint 0 (neutral, not disgusting or appealing)" (28). For their analyses, Lieberman and Lobel combined the two responses to form a "sexual attraction measure" ranging from -10 to 10 . They calculated each subject's "total sexual attraction score" by adding the sexual attraction scores for all of the subject's opposite-sex peers.

They measured moral attitudes toward third-party sexual practices in different ways in the two studies. In Study 1, subjects read two vignettes (based on the Markand-Julie vignette used by Haidt 2001) describing consensual and secret sex between siblings or peer-group members that was enjoyed by both participants and had no chance of leading to pregnancy. "For each vignette, subjects indicated how wrong it would be for the individuals described to start a sexual relationship and, separately, to get married on a scale ranging from - 5 (very morally wrong) to 5 (morally ok); midpoint 0 (neutral, not morally wrong or morally ok)" (Lieberman and Lobel 2012: 29). Scores for each vignette were combined to calculate a "morality dependent measure toward third-party peer sex and...third-party sibling sex" (29).

In Study 2, subjects ranked 10 behaviors, including sibling and intra-peer-group sex, in order of how morally wrong they perceived them to be.

Was the Westermarck-inspired hypothesis - that time spent coresiding with peers would be associated with increased moral opposition to third-party intra-peer-group sex-supported? In Study 1, Lieberman and Lobel found no statistically significant effect of time spent coresiding with peers on moral attitudes toward third-party peer sex. That is, people who spent more time coresiding with opposite-sex peers were not more likely to say it would be morally wrong for two peer-group members to start a sexual relationship or to get married.

In Study 2, however, they did find a statistically significant effect. When rank ordering 10 behaviors from most to least morally wrong, people who spent more time coresiding with opposite-sex peers ranked "Two Kibbutz classmates having sex" slightly lower (i.e., more morally wrong). The average rank of "Two Kibbutz classmates having sex" was $8.86(\mathrm{SD}=1.55)$, which was just above "Speeding on the highway" (average rank=6.66) and below the highest ranked behavior, "Converting to another religion" (average rank=9.00). The average rank of "A brother and sister having sex" was much lower at $3.76(\mathrm{SD}=2.15)$. Subjects' total coresidence duration with opposite-sex peers had a correlation of -.34 with their ranking of intra-peer-group sex. Lieberman and Lobel found that the association between coresidence duration and rank ordering for intra-peer-group sex was entirely mediated by personal sexual aversion-i.e., total coresidence duration did not predict rank ordering when controlling for subjects' sexual attraction/aversion toward their opposite-sex peers.

Lieberman and Lobel (2012: 32) conclude that their findings 
provide the missing psychological link for past studies documenting the virtual absence of marriage between coreared Kibbutz peers (Shepher 1983) - marriage rates were likely reduced not only because of mating opportunities outside the Kibbutz...but also inherent sexual aversions that developed to those within....These results support Westermarck's claim that "aversions which are generally felt readily lead to moral disapproval"....

But Lieberman and Lobel (2012) seem to be significantly overstating their case. The relationship between coresidence duration with (and sexual aversion toward) opposite-sex peers and "moral views relating to sex between peers" (30) was extremely weak. Again, Lieberman and Lobel's Study 1 did not find any effect of total coresidence duration on reported moral attitudes toward third-party sex. Study 2 found that coresidence duration (mediated by sexual aversion) had a very small effect on where people placed "Two Kibbutz classmates having sex" when rank ordering 10 behaviors from most to least immoral. But subjects ranked "A brother and sister having sex" on average 5.1 places lower than they ranked "Two Kibbutz classmates having sex," despite the fact that they had much closer contact with their non-sibling classmates during the supposedly critical period for developing sexual aversion. There is no evidence that they regarded kibbutz peer-group members having sex as genuinely immoral. On the other hand, they clearly regarded sibling sex as immoral.

The vicarious disgust hypothesis was a possible solution to the moralization problem, but not to the representation problem. Even if it were empirically supported, it would not explain why our ancestors came to believe that sex between siblings but not childhood coresidents is morally problematic. (The representation problem did not arise in kibbutzim, because we know that peer-group member was made into a socially significant category via social engineering.) But, as the evidence reviewed above suggests, there is no compelling evidence for a psychological mechanism that converts disgust in general-or Westermarckian sexual aversion specificallydirectly into moral condemnation.

\section{Alternative theories of incest taboos}

Incest taboos vary enormously across time and place, and there is no specific prohibition found in all societies. Even the taboo on sibling sex is far from being universal. Many traditional societies simply lacked norms concerning sibling incest (Thornhill 1991). For at least two-and-a-half centuries in Roman Egypt there seems to have been a positive preference for sibling marriage among commoners (Hopkins 1980). For one-and-a-half millennia Zoroastrians practiced sibling as well as parent-child marriage with strong encouragement from their religious authorities (Scheidel 1996). Some cultures that did have sibling incest taboos nevertheless made exceptions for the ruling families (Middleton 1962).

Any society's norms governing sex will be shaped by a panoply of historical, sociological, and evolutionary forces, all of which interact with human biological dispositions. There is almost certainly no single explanation of the sibling incest taboo that fully explains every instance of it. But it may be possible to identify 
factors that contributed to the development or persistence of the taboo in many cultures.

Theories of incest taboos can be divided into two general categories: intentional and selectionist. According to intentional theories-which can also be described as sociological-taboos were (consciously or unconsciously) designed by people to serve some (perceived) function. According to selectionist theories, taboos are the direct or indirect product of natural selection. That is, natural selection could (directly) favor individuals or groups with adaptive taboos, or it could (indirectly) endow people with adaptions from which taboos emerge as a byproduct. (Westermarck's hypothesis is selectionist, with natural selection producing the taboo indirectly via the Westermarck effect.) Again, different combinations of forces may shape the incest taboos of different societies. Natural selection always plays some role in cultural evolution by default because all cultural innovations are subject to natural selection. Regardless of how cultural practices originate, individuals or groups with more adaptive variants tend to proliferate.

Sex and marriage taboos may have profound implications for group functioning and adaptedness. Many social scientists in the twentieth century believed that, without the nuclear family incest taboo forcing people to make alliances outside the family unit, distinctively human society would be impossible. Lévi-Strauss (1956: 278), for example, declared:

it will never be sufficiently emphasized that, if social organization had a beginning, this could only have consisted in the [nuclear family] incest prohibition....It is there, and only there, that we find a passage from nature to culture, from animal to human life, and that we are in a position to understand the very essence of their articulation.

The fact that sibling and parent-child incest taboos are not universal casts doubt on the claim that they are the distinguishing features of human social life, but it is true that forced exogamy can foster interfamilial cooperation. Sex and marriage taboos can have other effects that influence group adaptedness in ways that could not be foreseen by any human designer. Schulz et al. (2019) argue that the Catholic Church's ban on cousin marriage triggered a cascade of cultural changes that made Westerners more individualistic, independent, and impersonally prosocial and less conformist and loyal to their ingroup. The taboo on sibling sex and marriage may have conferred advantages to groups that adopted it, which help account for its spread.

This section considers two promising sociological theories of incest taboos: they were established (a) to maintain social cohesion within family units or (b) in response to recognition of the dangers of inbreeding. The social cohesion theory turns out to be subject to versions of the representation and moralization problems, and probably does not explain the origin of the nuclear family incest taboo, though it may help explain its persistence. The recognition hypothesis is not subject to the representation and moralization problems, and it is supported by some suggestive evidence. 


\section{The social cohesion hypothesis}

According to Shor and Simchai (2009), people in small and highly cohesive "nonvoluntary groups" will suppress their sexual attraction to each other and/or establish norms against ingroup sexual relations. People do this because they are aware that ingroup sexual relationships will threaten the group's unity and "may even lead to its dissolution" (1814). People also fear the potential awkwardness that would ensue if they are rebuffed by, or have a failed romantic relationship with, someone with whom they must continue living in close contact. In Shor and Simchai's words:

when the institutional frame (be it family or any other small nonvoluntary group) is greatly cohesive and associations are dense, individuals identify the social and personal price of intimate dyadic relationships in terms of both group cohesiveness and potential embarrassment. Under such conditions, any expression of sexual emotions or drives may be consciously or unconsciously suppressed. (1814)

They marshal evidence for this theory from an unlikely source, namely, the same kibbutzim that are usually held up as supporting Westermarck. Proponents of Westermarck claim that coreared kibbutzniks felt sexual aversion toward each other in the absence of a taboo on intra-peer-group sex (Shepher 1971, 1983). Shor and Simchai found evidence that this is doubly wrong. Careful interviews with former kibbutzniks revealed that they did not typically feel sexual aversion toward childhood coresidents, and in many kibbutzim there was a taboo on intra-peer-group sex. Most of Shor and Simchai's interviewees felt attraction to at least one of their childhood coresidents: $33.3 \%$ reported "strong" and $20 \%$ reported "moderate" sexual attraction toward at least one peer-group member (1822). Slightly less than half reported sexual indifference, and almost no one reported sexual aversion. Many interviewees said that their peer group had norms against forming intragroup romantic relationships, and some said that they avoided making romantic overtures for fear of embarrassment. Kibbutzniks who described their peer group as being relatively cohesive were considerably more likely to report feeling sexual indifference toward their peers.

Shor and Simchai's claim that being part of a cohesive, nonvoluntary group leads at most to sexual indifference raises the question of why people typically feel sexual aversion toward their nuclear family members. They offer two possible answers. First, the sexual indifference we feel toward close family members in virtue of belonging to a cohesive, nonvoluntary group is reinforced by a strong cultural taboo, which turns the indifference into an aversion. Second, intrafamilial attraction may be more common than we usually think: "despite this powerful taboo, studies have found considerable rates of incest inside nuclear families, in America and elsewhere, including between siblings" (1833). The second suggestion is questionable in light of the evidence that a large proportion of people-including Shor and Simchai's own interviewees - report genuine aversion toward first- and third-party incest.

Shor and Simchai seem to have identified a real phenomenon, namely, people sometimes supress sexual attraction and/or establish norms against intragroup sex for the (more or less explicit) purpose of preserving group cohesion. But as an 
explanation for the incest taboo, this theory faces its own version of the representation and moralization problems. If I suppress my incestuous attractions to avoid damaging my close relationships with my family members, why should I support a rule prohibiting specifically incestuous attractions? That is to say, the content of my inhibition is avoid sex with fellow members of a cohesive, nonvoluntary group, but the content of the taboo is avoid sex with close family members (whether or not they are part of a cohesive, nonvoluntary group). And why should I care what other people do? Maybe I have a reason to want my own family members to suppress their attraction to me, but there is no reason to be concerned with the desires of third parties.

Even if Shor and Simchai's social cohesion hypothesis does not account for the origin of the sibling incest taboo, it may help explain the power and resilience of the taboo. Many nuclear families are relatively cohesive, nonvoluntary groups, and our tendency to suppress sexual attraction within such groups may reinforce incest taboos.

\section{The recognition hypothesis}

According to the recognition hypothesis, people recognized the link between inbreeding and birth defects. In hunter-gatherer and other small-scale societies, the birth of physically or mentally disabled people could burden the entire group. People had clear reasons to oppose third-party sexual behavior likely to produce offspring who would never become effective workers or warriors. After incest prohibitions were established, many societies_-including Western societies_-forgot their original purpose.

Burton (1973) was the first person to argue that incest prohibitions were established in response to conscious recognition of the dangers of inbreeding. He reported his impression, based on a "cross-cultural study of resistance to temptation," that "the most common reason given in both primitive and modern societies for the incest taboo is that it produces bad stock" (504-505).

In a more systematic study, Durham (1991: 347-348) found evidence for fairly widespread recognition of the dangers of inbreeding. He investigated the "consequences of [incest] taboo violations, real or hypothetical," according to people in 60 cultures. In 40 of the cultures, people reported that some negative socially or divinely imposed consequence would follow from incest. In 29, people reported that incest was punished by a social sanction, "most commonly death." In 16, "there was mention of a supernatural sanction, most commonly disease or death" (347). (In five cultures people who engaged in incest were subject to social sanctions and were considered liable for supernatural punishment.) Most important, in 20 of these societies-i.e., one-half of those that reported some sort of negative consequence for incest-Durham found references to a " 'bad stock' argument." For several more of these societies there was ambiguous evidence, or evidence from other ethnographic databases, that they recognized the negative consequences of inbreeding for offspring. Durham also notes that there was a correlation between the richness of the ethnographic data for a given society and the chance that he could find evidence of 
a folk theory about incest producing disabled offspring (348-349, n. 56). Thus, 20 out of 60 is likely an underestimate of the proportion of societies that achieved and preserved awareness of the negative effects of inbreeding.

Durham (1991) made another discovery that he sees as supporting the recognition hypothesis: incest rules in different societies reflect the relative dangers of inbreeding. The risk that close inbreeding will produce disabled offspring varies among populations. Large, exogamous populations tend to accumulate more deleterious recessive alleles. Because reproductive partners are, on average, distantly related to each other, the partners are less likely to have inherited the same deleterious mutations. Consequently, the mutations are less likely to be weeded out through the production of nonviable homozygotes. This makes inbreeding relatively dangerous. In contrast, reproductive partners in small, endogamous populations must be relatively closely related. In these populations, deleterious recessive alleles will be more quickly weeded out, making inbreeding less dangerous. The data analyzed by Durham suggest that "small endogamous populations do seem to have less extensive incest taboos than do their exogamous counterparts" (356). He suggests that taboos were tailored to the relative risks of inbreeding in different societies by human design. However, the data might also be explained as a consequence of natural selection favoring groups with locally adaptive taboos.

What about the sibling incest taboo in Western societies? The feeling of visceral disgust that incest arouses (Royzman et al. 2008) is not typically bound up-at least not consciously-with awareness of any negative consequences for offspring. In fact, until the 1960s there was a near scientific consensus in the West that inbreeding does not pose any dangers (Wolf 2004b: $1-3$ ). ${ }^{3}$ Now that the risks of inbreeding are widely known, people do often cite this as a reason to oppose incest, though they frequently cite psychological harm to the participants, and many say that incest is wrong in principle regardless of the consequences (Royzman et al. 2015). It is possible that our predecessors established the sibling incest taboo in response to recognition of the dangers of close inbreeding, and we retained the taboo after (temporarily) forgetting its original purpose.

There is evidence that this is exactly what happened with the taboo on cousin sex. Marriage between first cousins is perfectly accepted-if not encouraged-in many cultures, and used to be common in the West. In the late sixth century, Pope Gregory I claimed that it was prohibited because of the consequences for offspring:

A certain secular law in the Roman State allows that the son or daughter of a brother and sister, or of two brothers or two sisters may be married. But we have learned from experience that the offspring of such marriages cannot thrive. Sacred law forbids a man to uncover the nakedness of his kindred.

\footnotetext{
3 Most of Westermarck's contemporaries rejected his theory of inbreeding depression. Malinowski (1927: 243) asserted that "biologists are in agreement on the point that there is no detrimental effect produced upon the species by incestuous unions" (quoted in Wolf 2004b: 2). This (near) consensus lasted into the 1950s, and went largely unquestioned at a conference devoted to the incest taboo held at Stanford in 1956 (Aberle et al. 1963; Wolf 2004b: 3). Mainstream scientific opinion did not reverse until the 1960s in response to advances in genetics (Aberle et al. 1963: 256-257).
} 
Hence it is necessary that the faithful should only marry relations [at least] three or four times removed. (quoted in Durham 1991: 331)

Theoretically, the same thing could have happened with the sibling incest taboo. Alternatively, self-interest may have been the true reason for the Catholic Church's ban on cousin marriage. In the fourth century the Church established a number of laws - including prohibitions on adoption, polygyny, and cousin marriage - that increased the likelihood of people dying without heirs, in which case their property was inherited by the Church (Goody 1983; Prinz 2007: 231-232). In any case, the fact that Westerners continue to taboo sex and marriage between first cousins suggests that taboos can persist and continue to elicit emotional commitment long after their original purpose has been forgotten. Cultural evolution is often conservative, and for good reason. It is usually adaptive for people to accept the beliefs, values, and practices that they inherit unless they have a compelling reason to reject them (Henrich 2016). And, as Buchanan and Powell (2018: 251-252) observe, the elements of a culture are interconnected. Norms - particularly those that "implicate group identity or moral identity"-may become "culturally entrenched," since they "occupy a central, highly connected position in the cultural web." It may be possible for culturally entrenched taboos to be transmitted down the generations even if the original justification is forgotten.

According to the recognition hypothesis, people in the distant past noticed that sexual relations between those with certain biological relationships-including siblings - tended to lead to negative consequences for offspring. There is no representation problem for this theory. If sex between childhood coresidents who were not siblings led to negative consequences, then people would likely have noticed this and established a taboo to keep childhood coresidents apart. But our biology does not work that way, so childhood coresident never became an especially important social category.

\section{Discussion}

The widespread prohibition on sibling incest has been held up by many scholars as the best or one of the best examples of a moral norm that has an evolutionary explanation. According to Westermarck's $(1891,1921)$ influential theory, we evolved to feel sexual aversion toward childhood coresidents (who are usually our siblings) as an adaptation for inbreeding avoidance. This aversion leads us to condemn incest as immoral, which explains the incest taboo. However, the representation and the moralization problems show that there is no logical connection between feeling sexual disgust toward one's own childhood coresidents and judging sibling sex to be immoral. I have argued that Westermarck's account of the sibling incest taboo is probably wrong.

Other moral norms for which evolutionary explanations have been proposed will have to be analyzed separately. However, there is reason to believe that representation and moralization problems are pervasive. Instincts to have empathy for people we grew up with or to retaliate when someone harms us do not lead directly to moral 
norms such as everyone ought to care for their children or anyone who forcibly takes the property of another person should be punished. The gap between the content of our instincts and moral norms would help explain the fact that there is virtually no substantive universal moral norm (Prinz 2008), despite the fact that basic instincts are universal. As noted, even the prohibition on nuclear family incest is far from being a human universal (Thornhill 1991). However, moral variation is not infinite. Sripada and Stich (2006: 284) observe that "norms tend to cluster under certain general themes," and Curry et al. (2019) found that categories of behavior related to cooperation are especially likely to be moralized across cultures. The appearance of general themes in morality does not necessarily mean that moral norms are determined by instincts. Across cultures people with a capacity for normative reasoning are endowed with similar impulses, face some of the same challenges, and are subject to some of the same selection pressures. It is not surprising that general themes would emerge independently in different moral systems even if a wider range of variation is theoretically possible given the constraints imposed by our biology.

No one believes that every one of our moral beliefs can be explained as the direct product of natural selection. On all accounts, sociological factors also exert at least some influence. But a number of scholars believe that certain core, widespread moral norms are the more or less direct expression of biologically based adaptations. Street (2006: 119-120) assumes that "natural selection has had a tremendous direct influence on... our 'more basic evaluative tendencies', and...these basic evaluative tendencies, in their turn, have had a major influence on the evaluative judgements we affirm." Even this qualified position may be too strong. Our evaluative tendency to view incest as immoral is among the most "basic" that we have. Yet there is reason to believe that our opposition to incest not only was not but also could not have been directly shaped by natural selection via an instinct with different content.

Acknowledgements I am grateful to Roger Crisp, Guy Kahane, Andreas Mogensen, Neven Sesardić, and two anonymous reviewers for helpful comments on earlier drafts of this paper.

Open Access This article is licensed under a Creative Commons Attribution 4.0 International License, which permits use, sharing, adaptation, distribution and reproduction in any medium or format, as long as you give appropriate credit to the original author(s) and the source, provide a link to the Creative Commons licence, and indicate if changes were made. The images or other third party material in this article are included in the article's Creative Commons licence, unless indicated otherwise in a credit line to the material. If material is not included in the article's Creative Commons licence and your intended use is not permitted by statutory regulation or exceeds the permitted use, you will need to obtain permission directly from the copyright holder. To view a copy of this licence, visit http://creativecommons.org/licen ses/by/4.0/.

\section{References}

Aberle DF, Bronfenbrenner U, Hess EH, Miller DR, Schneider DM, Spuhler JN (1963) The incest taboo and the mating patterns of animals. Am Anthropol 65:253-265

Boehm C (1999) Hierarchy in the forest: the evolution of egalitarian behavior. Harvard University Press, Cambridge

Buchanan A, Powell R (2018) The evolution of moral progress: a biocultural theory. Oxford University Press, New York 
Burton RV (1973) Folk theory and the incest taboo. Ethos 1:504-516

Curry OS, Mullins DA, Whitehouse H (2019) Is it good to cooperate? Testing the theory of morality-ascooperation in 60 societies. Curr Anthropol 60:47-69

de Waal FBM (1999) The end of nature versus nurture. Sci Am 281:94-99

Durham WH (1991) Coevolution: genes, culture, and human diversity. Stanford University Press, Stanford

Eibl-Eibesfeldt I (1989) Human ethology. Aldine de Gruyter, New York

Goody J (1983) The development of the family and marriage in Europe. Cambridge University Press, Cambridge

Haidt J (2001) The emotional dog and its rational tail: a social intuitionist approach to moral judgment. Psychol Rev 108:814-834

Haidt J, Graham J (2007) When morality opposes justice: conservatives have moral intuitions that liberals may not recognize. Soc Justice Res 20:98-116

Henrich J (2016) The secret of our success: how culture is driving human evolution, domesticating our species, and making us smarter. Princeton University Press, Princeton

Hopkins K (1980) Brother-sister marriage in Roman Egypt. Comp Stud Soc Hist 22:303-354

Landy JF, Goodwin GP (2015) Does incidental disgust amplify moral judgment? A meta-analytic review of experimental evidence. Perspect Psychol Sci 10:518-536

Lévi-Strauss C (1956) The family. In: Shapiro HL (ed) Man, culture, and society. Oxford University Press, New York, pp 261-285

Lieberman D, Lobel T (2012) Kinship on the kibbutz: coresidence duration predicts altruism, personal sexual aversions and moral attitudes among communally reared peers. Evol Hum Behav 33:26-36

Lieberman D, Tooby J, Cosmides L (2007) The architecture of human kin detection. Nature 445:727-731

Machery E, Mallon R (2010) Evolution of morality. In: Doris JM (ed) The moral psychology handbook. Oxford University Press, Oxford, pp 3-46

Malinowski B (1927) Sex and repression in savage society. Kegan Paul, Trench, Trubner, London

May J (2014) Does disgust influence moral judgment? Australas J Philos 92:125-141

Middleton R (1962) Brother-sister and father-daughter marriage in ancient Egypt. Am Sociol Rev 27:603-611

Millikan RG (1989) Biosemantics. J Philos 86:281-297

Pizarro D, Inbar Y, Helion C (2011) On disgust and moral judgment. Emot Rev 3:267-268

Prinz J (2007) The emotional construction of morals. Oxford University Press, Oxford

Prinz J (2008) Is morality innate? In: Sinnott-Armstrong W (ed) Moral psychology, vol 1. The evolution of morality: adaptations and innateness. MIT Press, Cambridge, pp 367-406

Royzman EB, Leeman RF, Sabini J (2008) "You make me sick": moral dyspepsia as a reaction to thirdparty sibling incest. Motiv Emot 32:100-108

Royzman EB, Kim K, Leeman RF (2015) The curious tale of Julie and Mark: unraveling the moral dumbfounding effect. Judgm Decis Mak 10:296-313

Ruse M, Wilson EO (1986) Moral philosophy as applied science. Philosophy 61:173-192

Scheidel W (1996) Brother-sister and parent-child marriage outside royal families in ancient Egypt and Iran: a challenge to the sociobiological view of incest avoidance? Ethol Sociobiol 17:319-340

Schnall S, Haidt J, Clore GL, Jordan AH (2015) Landy and Goodwin (2015) confirmed most of our findings then drew the wrong conclusions. Perspect Psychol Sci 10:537-538

Schulz JF, Bahrami-Rad D, Beauchamp JP, Henrich J (2019) The Church, intensive kinship, and global psychological variation. Science 366:eaau5141

Sesardic N (1998) From biological inhibitions to cultural prohibitions, or how not to refute Edward Westermarck. Biol Philos 13:413-426

Sesardic N (2004) From genes to incest taboos: the crucial step. In: Wolf AP, Durham WH (eds) Inbreeding, incest, and the incest taboo: the state of knowledge at the turn of the century. Stanford University Press, Stanford, pp 109-120

Shepher J (1971) Mate selection among second generation kibbutz adolescents and adults: incest avoidance and negative imprinting. Arch Sex Behav 1:293-307

Shepher J (1983) Incest: a biosocial view. Academic Press, New York

Shor E, Simchai D (2009) Incest avoidance, the incest taboo, and social cohesion: revisiting Westermarck and the case of the Israeli kibbutzim. Am J Sociol 114:1803-1842

Silk JB (2009) Nepotistic cooperation in non-human primate groups. Philos Trans R Soc B 364:3243-3254 
Sripada CS, Stich S (2006) A framework for the psychology of norms. In: Carruthers P, Laurence S, Stich S (eds) The innate mind, vol 2. Culture and cognition. Oxford University Press, Oxford, pp 280-301 Street S (2006) A Darwinian dilemma for realist theories of value. Philos Stud 127:109-166

Thornhill NW (1991) An evolutionary analysis of rules regulating human inbreeding and marriage. Behav Brain Sci 14:247-261

Westermarck E (1891) The history of human marriage. Macmillan, London

Westermarck E (1921) The history of human marriage, vol 2, 5th edn. Macmillan, London

Wheatley T, Haidt J (2005) Hypnotic disgust makes moral judgments more severe. Psychol Sci 16:780-784

Williams B (1983) Evolution, ethics, and the representation problem. In: Bendall DS (ed) Evolution from molecules to men. Cambridge University Press, Cambridge, pp 555-566

Wilson EO (1998) Consilience: the unity of knowledge. Vintage Books, New York

Wolf AP (2004a) Explaining the Westermarck effect: or, what did natural selection select for? In: Wolf AP, Durham WH (eds) Inbreeding, incest, and the incest taboo: the state of knowledge at the turn of the century. Stanford University Press, Stanford, pp 76-92

Wolf AP (2004b) Introduction. In: Wolf AP, Durham WH (eds) Inbreeding, incest, and the incest taboo: the state of knowledge at the turn of the century. Stanford University Press, Stanford, pp 1-23

Wolf AP, Durham WH (eds) (2004) Inbreeding, incest, and the incest taboo: the state of knowledge at the turn of the century. Stanford University Press, Stanford

Publisher's Note Springer Nature remains neutral with regard to jurisdictional claims in published maps and institutional affiliations. 